\title{
Autism: A Review of Biological Bases, Assessment, and Intervention
}

\author{
Martin A. Volker and Christopher Lopata \\ University at Buffalo, The State University of New York
}

\begin{abstract}
The number of children classified with autism in US schools has risen sharply over the past decade. School psychologists are being called upon with increasing frequency to assist in the identification, assessment, and treatment of these children. The diagnostic complexities and heterogeneity of the disorder make dealing effectively with this condition a considerable challenge for school personnel. Additionally, the biological basis of the disorder necessitates the involvement of medical personnel in both assessment and intervention. This article reviews recent findings regarding the genetics of autism, associated neurological features, best practice assessment, and empirically supported interventions.
\end{abstract}

Keywords: autism, autistic spectrum, genetics, assessment, intervention

Autistic disorder is characterized by substantial deficits in communication and social functioning, as well as restrictive, repetitive and stereotyped behaviors, all present before 3 years of age. Evidence suggests that autism is a heterogeneous condition with a strong genetic basis. Researchers now believe there may be as many as $15+$ genes involved in the disorder (Santangelo \& Tsatsanis, 2005), with variations in symptom expression across cases occurring partially as a result of different genetic influences. Further complicating the situation, considerable debate exists as to whether conditions at the higher functioning end of the autistic spectrum (i.e., high functioning autism, Asperger's disorder, and high functioning PDD-NOS) are separate disorders or simply different expressions of the same underlying condition (see Matson, 2007; Mayes \& Calhoun, 2004; Volkmar, Lord, Bailey, Schultz, \& Klin, 2004). Given this state of affairs, from this point forward, the term autism will refer specifically to autistic disorder, whereas the acronym ASD will be used to refer collectively to the broader

Martin A. Volker, PhD, and Christopher Lopata, PsyD, University at Buffalo, The State University of New York, Buffalo, NY.

Correspondence concerning this article should be addressed to Martin A. Volker, 409 Christopher Baldy Hall, Department of Counseling, School, and Educational Psychology, Graduate School of Education, University at Buffalo, The State University of New York, Buffalo, NY. E-mail: mvolker@buffalo.edu spectrum of autistic disorder, Asperger's disorder, and PDD-NOS.

\section{Prevalence and Associated Features}

The current prevalence rate for autistic disorder is estimated at approximately 10 to 16 cases per 10,000 people, whereas the prevalence for the broader PDD spectrum (excluding Rett's disorder and childhood disintegrative disorder) is estimated at 60 cases per 10,000 (Fombonne, 2005a). Of great importance to school professionals, is that the number of students served under the IDEA category of Autism has risen sharply from 15,580 in 1992 (when the United States Department of Education first began tracking autism service rates) to 192,643 in 2005 (US Department of Education, 2007). This rise is likely resulting from increasing awareness of the broader spectrum of conditions to which autistic disorder belongs. Whatever the reason for the increase, school psychologists are now required to be more involved in the assessment and treatment of ASDs than ever before.

Autism tends to involve a number of other important associated features. These include mental retardation (MR), seizures, a greater proportion of affected males, and comorbidity with other genetic syndromes. The rate of MR in autism is around 70\% (Fombonne, 2005a), with lower rates of impaired intellectual functioning for the broader spectrum that includes PDDNOS and Asperger's disorder. A recent epidemiological study of preschoolers with pervasive developmental disorders in England indicated a 
MR comorbidity rate of $69.2 \%$ for autism, $7.6 \%$ for PDD-NOS, and 0\% for Asperger's disorder (Chakrabarti \& Fombonne, 2001).

The association between ASDs and seizure disorders is also well recognized. Estimates of epilepsy within autism range from $8 \%$ to $42 \%$ of autism cases (Canitano, Luchetti, \& Zappella, 2005). The prevalence of seizures in ASDs appears to vary with age, cognitive ability, and the extent of neurological impairment. Age of seizure appearance is bimodal, with a peak in early childhood and another in adolescence (Volkmar \& Nelson, 1990). There is an inverse relationship between level of cognitive functioning and the presence of seizures in cases of ASDs (Tuchman, Rapin, \& Shinnar, 1991). School psychologists are advised to consult Wodrich, Kaplan, and Deering (2006) for information useful in assessment and service planning for children with epilepsy.

In a review of epidemiological surveys of autism and pervasive developmental disorders, Fombonne (2005a) reported a mean male to female ratio of $4: 1$. Studies suggest that the gender ratio varies with level of cognitive functioning and degree of overall impairment, with closer to even representation of males and females (e.g., 1.95:1 to 1.3:1) in the moderate/ severe to profound MR range and a much higher male to female ratio (e.g., 6.7:1 to 5.5:1) in the high functioning, non-MR range (Fombonne, 2005b; Yeargin-Allsopp et al., 2003). It is likely that these findings reflect sex-linked aspects of the underlying neurological pathology.

A number of known genetically based disorders are associated with autism (see Cohen et al., 2005 for a detailed review). The two most frequently reported are fragile $\mathrm{X}$ syndrome and tuberous sclerosis. Autistic features occur in approximately $15 \%$ to $25 \%$ of fragile X syndrome cases (Rogers, Wehner, \& Hagerman, 2001) and $25 \%$ to $50 \%$ of tuberous sclerosis cases (Wiznitzer, 2004). However, despite the comorbidity of autism with these syndromes, such known genetic disorders appear to account for no more than $10 \%$ of all autism cases at this time (Fombonne, 2005a). Overall, this means that school psychologists should anticipate the possible presence of autistic symptoms when dealing with these other disorders, and plan assessment, intervention, and staff training with this in mind. However, it also means that, for the time being, the majority of autism cases encountered will not involve an obvious genetic cause.

\section{Genetics}

There is considerable evidence in support of a genetic etiology for autism. In twin studies, the median concordance rate for autistic disorder is approximately 60\% in monozygotic twins; when a broader phenotype definition is used, concordance increases to a median value of $91 \%$ (Fombonne, 2005a). An autism prevalence rate of approximately $4 \%$ is seen among siblings of children diagnosed with autism, with an adjusted estimate of $6 \%$ to $8 \%$ sibling recurrence risk when taking into account the tendency of some parents to forgo further pregnancies (Bonora, Lamb, Barnby, Bailey, \& Monaco, 2006). This is in sharp contrast to the much lower prevalence rate of $0.1 \%$ to $0.16 \%$ observed in the general population (Fombonne, 2005a).

Reviews of genome-wide scans concerned with autism have revealed at least one positive genetic linkage on almost every chromosome (Santangelo \& Tsatsanis, 2005; Yang \& Gill, 2007), with 188 specific gene candidates having been examined (Yang \& Gill, 2007). Because few of these results have been replicated, only those chromosomal regions and genes with more positive support and theoretical justification (e.g., a purported connection to neural development or regulation) will be reviewed. (Using international nomenclature, the chromosomal notation in this section provides the chromosome number first, followed by $q$ if reflecting the long arm or $p$ if the short arm of the chromosome, and then numbers that reflect the regional bands).

\section{Chromosome 15}

The 15q11-q13 chromosomal region has shown different mutations that separately account for Angelman syndrome (caused by maternal $U B E 3 A$ deletion or deactivation), PraderWilli syndrome (caused by paternal SNRPN deletion), and $1 \%$ to $3 \%$ of the cases of autistic disorder that are related to maternal duplications or triplications (Dykens, Sutcliffe, \& Levitt, 2004). These maternal chromosome 15 malformations are the most frequently observed known genetic mutation in autism cases outside 
of those involving fragile $\mathrm{X}$ syndrome (see article in this special issue) or tuberous sclerosis. It is also noteworthy that the $15 q 11-13 q$ region is a locus of interest in epilepsy research (Tuchman \& Rapin, 2002), a potentially important fact, given the prevalence of epilepsy in ASDs.

The 15q11-q13 interval contains, among other things, the $\mathrm{GABA}_{\mathrm{A}}$ receptor complex, which consists of several related genes. $\mathrm{GABA}_{\mathrm{A}}$ is the primary inhibitory neurotransmitter in the brain and it acts through the $\mathrm{GABA}_{\mathrm{A}}$ receptors. A malfunction in one or more genes of the $\mathrm{GABA}_{\mathrm{A}}$ receptor complex is a major hypothesis for explaining which specific aspect of the 15q11-q13 interval may account for the increased risk of autism (Sutcliffe \& Nurmi, 2003).

\section{Chromosome 7}

Though a specific autism-related gene on chromosome 7 has yet to be identified, genomewide scans have repeatedly suggested a connection with this chromosome (Santangelo \& Tsatsanis, 2005). Specific follow-up studies have focused on the reelin gene (RELN at 7q22) and the FOXP2 gene (7q31). The reelin protein is critically involved in the guidance of neuronal migration during early development, and fosters synaptic plasticity in the adult brain (Fatemi, 2005). However, studies searching for associations between the reelin gene itself and autism have so far yielded mixed results (Bonara et al., 2006).

A connection between autism and the FOXP2 gene has proven elusive. A mutation in this gene has been associated with a severe speech and language disorder across three generations of the same family (Lai, Fisher, Hurst, VarghaKhadem, \& Monaco, 2001). However, other studies have demonstrated that FOXP2 does not appear to be associated with more common forms of language impairment or autism (Lennon et al., 2007; Newbury et al., 2002). Currently, more refined studies of the 7q21.2-q36.2 region are needed to explain the linkage between this region and autism.

\section{Other Gene Sites}

Mutations in the neuroligin (Xq13 and Xp22.3; Laumonnier et al., 2004; Yan et al., 2005), neurexin (2p16; Feng et al., 2006), and
SHANK3 (22q13.3; Durand et al., 2007) genes have separately been associated with a small number of autism cases. Neuroligins and neurexins are cell adhesion proteins. Neuroligins form the postsynaptic end and neurexins form the presynaptic end of a tether between two cells during synapse development (Graf, Zhang, Jin, Linhoff, \& Craig, 2005). SHANK3 is a scaffolding protein that assists in dendrite growth and positioning within excitatory synapses (Roussignol et al., 2005). Disruptions in the formation or transportation of any one of these proteins are likely to result in neural synaptic abnormalities and potentially affect the relative level of excitatory versus inhibitory activity in affected brain regions.

The elevated platelet levels and unusual serotonin synthesis patterns observed in the brains of some individuals with autism (Mulder et al., 2004) have motivated researchers to examine serotonin-related genes for possible etiological significance. Despite receiving only mixed support for linkage from whole genome scans, variations in the serotonin transporter gene (SLC6A4 at 17q11.1-q12) have shown associations with autism using other methods (see Bespalova, Reichert, \& Buxbaum, 2005). More recently, Coutinho et al. (2007) found evidence of interactions between serotonin transporter gene variants and variations in the beta 3 integrin gene (ITGB3 at 17q21.32), which were associated with autism and platelet serotonin levels.

\section{Neurological Correlates of Autism}

Given the heterogeneity in symptom presentation of ASDs, it should be no surprise that considerable variation in neurological differences has been observed and that consistencies have been hard to come by. Given this state of affairs, this review will focus on more consistently reported neurochemical, developmental, structural, and functional brain abnormalities in ASDs from across methodologies (e.g., stereology, MRI, fMRI, PET). Broadly speaking, these consistencies include unusual serotonin levels and synthesis patterns; abnormal head size and brain growth trajectory; and structural and functional differences in the cerebral cortex, cerebellum, and amygdala. 


\section{Abnormal Serotonin Levels}

Blood platelet serotonin levels are elevated in children with autism and PDD-NOS. Approximately one third present with platelet hyperserotonemia (Mulder et al., 2004). Furthermore, positron emission tomography (PET) studies of children with autism have revealed evidence of diminished serotonin synthesis in the frontal cortex and thalamus of males, increased levels of serotonin synthesis in part of the cerebellum of male subjects, and an abnormal age-related trend in serotonin synthesis regardless of gender (Chugani et al., 1999).

\section{Brain Size and Growth}

Studies indicate that the brains of children with autism show a very unusual growth pattern (Aylward, Minshew, Field, Sparks, \& Singh, 2002). Children with autism tend to go through a period of accelerated head and brain growth soon after birth, which appears to subside sometime before age 24 months (Courchesne, Redcay, \& Kennedy, 2004). Once completed, this period is followed by a time of unusually slow brain growth relative to same age nonautistic peers, such that by sometime between middle childhood and early adolescence, average overall brain volume for those with autism does not appear to be substantially different from expectations for that age (Aylward et al., 2002; Courchesne et al., 2004).

The period of enlarged head circumference in early childhood is mirrored by unusually large overall brain size, substantially increased white brain matter in the frontal lobe, parietal lobe, and cerebellum, and increased gray brain matter in the frontal lobe and temporal lobe (Carper, Moses, Tigue, \& Courchesne, 2002). In males with autism between the ages of 2 and 4 years, $90 \%$ had a brain volume above the average for typical same age peers. In 2 to 3 -year-old children with autism, overall cortical white matter was $18 \%$ greater than normal, cortical gray matter was $12 \%$ greater than normal, and cerebellar white matter was $39 \%$ greater than expectation (Courchesne et al., 2001).

\section{Minicolumn Abnormalities}

When compared to controls, the brains of people diagnosed with autism show an unusual pattern of minicolumn arrangement. Minicolumns are believed to be the smallest vertical organizational units within the neocortex (Buxhoeveden \& Casanova, 2002). Typically, each minicolumn consists of between 80 and 100 neurons interwoven into a column-like structure that resembles a string of beads. In the brains of individuals with autism, the frontal and temporal lobe minicolumns appear to be smaller, more numerous, and are packed closer together. The constituent cells of these minicolumns also appear to be more spread out than is typical within the column structure (Casanova, Buxhoeveden, Switala, \& Roy, 2002a, 2002c). Similar findings were also reported for subjects with Asperger's disorder (Casanova, Buxhoeveden, Switala, \& Roy, 2002b).

These differences in minicolumn number and structure, coupled with evidence of white versus gray brain matter differences (Cassanova, 2004), and hypothesized communicative dysfunctions between brain regions (e.g., cerebellothalamo-cortical pathway and cerebello-limbic pathway dysfunctions; Dum \& Strick, 2006) have lead to the theory that autistic disorder involves excessive neural connectivity within local brain regions, but underconnectivity between larger, more distant brain regions (Courchesne \& Pierce, 2005). This theory has the potential to explain both the abnormal sensory tendencies observed in some people with autism and the occasional appearance of unusually strong isolated talents or "splinter skills" that exist within a larger unintegrated context.

\section{Cerebellar and Amygdalar Abnormalities}

Stereological studies have consistently reported reductions in the number of purkinje cells (Bauman \& Kemper, 2005) or reduction in the size of these cells (Fatemi et al., 2002) in the cerebella of people with autism. A recent review indicated that this abnormality was present in $72 \%$ of the known autopsied cases with autism in the literature (Palmen, van Engeland, Hof, \& Schmitz, 2004). The purkinje cell differences are found in people of all ages with autism and are believed to be of prenatal origin (Bauman \& Kemper, 2005). The purkinje cell size reduction is present despite a $7 \%$ overall larger cerebellum size in early childhood ( 2 to 4 years old; Sparks et al., 2002). There is also evidence of reduced reelin and Bcl-2 levels 
(Fatemi, Stary, Halt, \& Realmuto, 2001), as well as abnormalities in nicotinic receptors (Lee et al., 2002) within the cerebella of those with autism.

The amygdala, located in the temporal lobe region, appears to play a role in some autistic symptoms. In support of this, recent research has indicated that in male subjects with autism and no history of seizures, the amygdala demonstrated an abnormal pattern of development characterized by enlargement in childhood (Schumann et al., 2004) and a decreased number of neurons in adulthood (Schumann \& Amaral, 2006). Second, amygdala abnormalities have been associated with deviations in eye contact in both children with autism (Dalton et al., 2005) and in an extensively studied nonautistic adult subject with bilateral amygdala damage (Spezio, Huang, Castelli, \& Adolphs, 2007).

\section{Assessment}

Most children with autistic disorder will be identified before they reach school age. However, some lower functioning children and a greater number of higher functioning children from the broader spectrum of ASDs will require a diagnostic assessment at school age. Though specialty clinics exist in many areas of the country directed at the assessment of autism spectrum disorders, it is unlikely that such clinics will be able to keep up with the increasing demand for their services. The wait time for an evaluation at many clinics is already unacceptably long, given the need to diagnose and intervene as early as possible with ASDs. Most of the nonmedical aspects of an autism assessment could be performed within the school setting, though the team of school-based professionals involved would need the requisite training and experience with this population (see Noland \& Gabriels, 2004). School psychologists are well positioned in terms of training and role within the school to figure prominently into this assessment process.

In regard to school classification, the National Research Council (NRC, 2001) suggested that, given the evidence supporting early intervention and the reality that children frequently cannot access services for the treatment of autism without the diagnosis, the diagnosis and formal educational label should be applied as early as possible. They further recommended that all children diagnosed within the autism spectrum be eligible for special education services within the autism spectrum disorders category (i.e., Autism classification) regardless of severity (NRC, 2001).

Broadly speaking, the assessment of the child should include medical, genetics, audiological, psychological, speech/language, gross and fine motor, and educational evaluations (Cohen et al., 2005; NRC, 2001). The first four of these assessments are discussed in more detail here, as the critical aspects of the first three may be less familiar to school psychologists and the fourth is directly relevant to their specific role. The medical aspects of the evaluation are also worth knowing in more detail because school psychologists with this type of knowledge will be in a better position to advocate for medical evaluations that include the necessary components.

\section{Medical}

A complete physical examination should be conducted by a physician, which includes neurological status; measurements of height, weight, and head circumference growth curve; skin examination with a Wood lamp for evidence of tuberous sclerosis; and the noting of any physical dysmorphisms or malformations (Cohen et al., 2005). The tendency of many autistic children to mouth nonfood items and the prevalence of pica within this population suggest an increased risk of lead exposure and toxicity. Thus, lead levels should be tested as part of the medical evaluation (Filipek et al., 2000).

\section{Genetics}

As previously noted, autism clearly involves a strong genetic influence. However, only about $10 \%$ of cases involve a specific, identified genetic issue. As more progress is made on possible genetic causes of ASDs, this assessment step will take on greater significance. In the mean time, this step is necessary to rule out the possible presence of a known genetic condition related to autistic symptoms. The following guidelines for genetic screening in autism are available from the literature: 
(a) In general, when a known family history of a particular genetic disorder is present, screening for that genetic condition and related syndromes is warranted in any individual presenting with significant developmental concerns (Cohen et al., 2005).

(b) For most patients presenting with apparent nonsyndromal autism, Cohen et al. (2005) suggested that testing should include conventional karyotype and screening for the fragile $\mathrm{X}$ mutation. However, Filipek et al. (2000) warned that the probability of a positive result arising from these procedures is very low in cases of high functioning ASDs.

(c) When moderate to severe cognitive deficits are present, Cohen et al. (2005) recommended that the Bratton-Marshall test, a search of mucopolysaccharides in urine, and specific FISH studies for 15q11-q13 duplication and 22q13 deletion be added to the standard tests (Cohen et al., 2005).

\section{Audiological}

It is recommended that all young children with social and/or language delays receive a hearing evaluation to assess whether hearing difficulties play a role in the condition. In more severely delayed or behaviorally challenging cases, testing modifications may be necessary. A variety of different electrophysical procedures are available to assist in these situations, such as the evoked otoacoustic emissions test (OAE) or a frequency-specific auditory brainstem response (ABR) evaluation (see Filipek et al., 2000).

\section{Psychological}

The psychological evaluation should include a detailed family and developmental history; cognitive testing; assessment of adaptive, social, maladaptive, and atypical behaviors; and, to assist in the formulation of more specific treatment recommendations, a functional behavior assessment regarding more problematic behaviors likely to be the earliest targets of intervention. Potentially useful information is derived from interviews with the parents, teachers, and, if possible, the child; direct observa- tions of the child in relevant settings; and direct testing of the child.

The Autism Diagnostic Interview-Revised (ADI-R; Rutter, Le Couteur, \& Lord, 2003) and the Autism Diagnostic Observation Schedule (ADOS; Lord, Rutter, DiLavore, \& Risi, 1999) are currently considered the "gold standard" autism diagnostic instruments for research purposes (Santangelo \& Tsatsanis, 2005) by international consensus, and they are frequently used as part of the diagnostic battery at clinics specializing in the assessment of ASDs. Both instruments were designed using the autistic disorder diagnostic criteria from the Diagnostic and Statistical Manual of Mental DisordersFourth Edition (DSM-IV; American Psychiatric Association, 1994) and the International Classification of Diseases-10th Edition (ICD-10; World Health Organization, 1992). Studies of autism are now typically required to use at least one of these instruments in establishing the diagnosis in order for the study to be considered for federal funding or for publication in higher level journals.

ADI-R. The ADI-R (Rutter et al., 2003) is a semistructured interview administered to the subject's primary caregiver. It consists of 93 questions and takes from 90 to 180 minutes to administer. The ADI-R was designed to distinguish people with autism from people with language delays and mental retardation who have a minimum mental age of 2 years. The questions attempt to elicit detailed information regarding family history, early development, language and communication, social development and play behaviors, repetitive and restrictive behaviors, problem behaviors, possible regression of skills, and the presence of possible "splinter" skills or areas of unusual strength. Thus, the ADI-R provides for the structured gathering of important family and developmental history information, as well as detailed diagnostic information relating to atypical development. The scores from a subset of the ADI-R items contribute to a diagnostic algorithm. The items in the algorithm were selected based on their ability to discriminate between cases with and without autism. Cut scores are provided for the major domains (e.g., communication; social interaction; restricted and repetitive, stereotyped interests and behaviors; and early developmental delay) and suggest whether one has met the diagnostic criteria for that domain (Rutter et al., 
2003). In an early study of the ADI-R with preschool age children, Lord, Rutter, and Le Couteur (1994) reported intraclass correlations for domain scores ranging from .93 to .97 , substantial interrater agreement at the item level, and accurate classification of 24 out of 25 children who had clinical diagnoses of autistic disorder and 23 out of 25 children without autism who had significant cognitive and language impairments. (See Rutter et al., 2003 for further ADI-R measurement characteristics.)

ADOS. The ADOS (Lord et al., 1999) is a standardized behavioral observation and coding system that takes approximately 35 to 45 minutes to administer. It consists of a standardized series of activities that attempt to elicit social, play, and communication behaviors related to autism. There are four different ADOS modules. The module administered depends on the communication level and age of the examinee. Like the ADI-R, the item scores from the ADOS are put into a diagnostic algorithm that yields scores for a social domain, communication domain, and a total combined score. Cut scores are provided to suggest when diagnostic criteria have been met for a given domain (Lord et al., 1999). According to the manual, internal consistency ranged from .91 to .94 for the total score. When compared to consensus clinical diagnoses, ADOS sensitivities for discriminating between Autism and PDD-NOS combined versus non-ASDs ranged from .90 to .97 , while specificities ranged from .87 to .94 (see Lord et al., 1999 for further details).

The ADI-R and ADOS are each useful individually, but offer maximum diagnostic utility when used together (Risi et al., 2006). The ADOS grants direct observational information to offset the potential weaknesses of parent reported information, whereas the ADI-R allows for gathering broad information regarding the child's developmental history and current behavior through parent report in situations beyond the examiner's capacity to observe. Despite the clear strengths of these instruments, it must be clearly stated that the results and cut scores provided are not to be interpreted in isolation. They are guidelines meant to assist with diagnosis, but require the larger context of information from other sources (e.g., assessment results from other professionals on the assessment team). Additionally, it needs to be stressed that these instruments require signifi- cant training to be used properly and, in the case of the ADI-R, significant administration time. Though not necessarily efficient, these instruments are well-designed tools and offer school psychologists the opportunity for making greater contributions to the assessment process in ASDs.

Other instruments. When it is not possible to administer the ADI-R and/or ADOS in the school setting because of time and resource constraints, examiners should consider contributing information to the screening and diagnostic processes through some of the more abbreviated, yet useful instruments such as the Childhood Autism Rating Scale (CARS; Schopler, Reichler, \& Renner, 1988). Though an instrument like the CARS should not be used in isolation to diagnose autism, the information that it yields can be useful as part of a larger diagnostic assessment. This more limited information can be forwarded to the outside clinician(s) performing the rest of the diagnostic evaluation, perhaps as part of the initial referral.

A thorough review of instruments useful in the assessment of cognitive functioning and adaptive behaviors in ASDs is beyond the scope of this article. However, in terms of cognitive testing it is important for psychologists to take into account the language levels of the child with an ASD and make sure that the testing environment is properly prepared to maximize cooperation. This being said, many lower functioning children with autism may not be able to cope or comply with direct testing requirements even under the best of circumstances. (Brock, Jimerson, and Hansen [2006] and Noland and Gabriels [2004] are recommended for more detailed information regarding the assessment of children with ASDs in schools.)

\section{Interventions}

Significant progress has been made in the treatment of ASDs over the past 30 years. A comprehensive discussion of interventions for ASDs poses a significant challenge because of the multiple domains affected, highly variable symptom presentation, and range of interventions. Although a detailed discussion of individual models is beyond the scope of this paper, the following provides an overview of intervention research, with an emphasis on interventions supported by empirical research. Included in 
this section is a review of structured and naturalistic behavioral approaches, cognitivebehavioral approaches for high-functioning ASDs, and pharmacological interventions.

\section{Behavioral Interventions}

Behavioral interventions have been widely studied and identified as the predominant intervention for ASDs. The effectiveness of intensive 1:1 instruction was first highlighted in a study by Lovaas (1987), which found that two or more years of early intensive 1:1 behavioral treatment $(40+$ hours per week) resulted in significantly higher IQ scores and less restrictive educational placements for young children with autism. Since Lovaas' seminal study, a number of studies have supported the effectiveness of behavioral treatments for ASDs. Partial replications of Lovaas' manualized treatment and other studies using 1:1 intensive behavioral interventions have generally found significant improvements for children with ASDs in areas such as IQ, language, adaptive behaviors, autistic symptoms, and problem behaviors (e.g., Butter, Mulick, \& Metz, 2006; Eikeseth, Smith, Jahr, \& Eldevik, 2007; Harris \& Handleman, 2000; Howard, Sparkman, Cohen, Green, \& Stanislaw, 2005), as well as reductions in the need for special education services (Cohen, Amerine-Dickens, \& Smith, 2006; Smith, Groen, \& Wynn, 2000).

Despite empirical support for structured adult-directed behavioral intervention, it has been argued that the skills do not generalize across settings. To overcome this weakness, naturalistic behavioral interventions such as pivotal response training (PRT) and incidental teaching have taught skills in more typical settings (Schreibman \& Ingersoll, 2005). PRT uses applied behavior analysis principles in the child's most inclusive and natural settings (e.g., home, preschool). It is based on the premise that teaching pivotal behaviors such as responsivity to multiple cues, motivation, self-management, and self-initiation results in improvements in other collateral behaviors without having to teach the associated behaviors (Koegel, Koegel, \& Brookman, 2003). PRT uses the child's preferred activities to teach and reinforce skills using natural reinforcers in the environment that are directly and functionally related. Research reviews have reported positive affects of PRT on a range of speech and behavioral characteristics associated with ASDs (McConnell, 2002). Proponents assert that PRT can be less costly, burdensome, and time-demanding than approaches that teach individual behaviors (e.g., Koegel et al., 2003).

Incidental teaching is another form of naturalistic behavioral intervention in which the environment is carefully arranged such that children with ASDs are attracted to materials and express interest in an object. This is then used to prompt and shape child elaborations followed by granting access to the desired object (Rogers, 2000). Similar to PRT incidental teaching uses reinforcers in the natural environment that are functionally related to the target skills, which promotes greater generalization. Delprato (2001) reviewed 10 studies comparing traditional discrete trial teaching to more naturalistic teaching for language development in young children with autism and reported that naturalistic teaching resulted in better language acquisition and generalization. A review by Goldstein (2002) of communication interventions concluded that both discrete trial training and milieu approaches (e.g., incidental learning, PRT) were effective and there did not appear to be evidence that naturalistic interventions were clearly more effective. A comprehensive report on educating children with ASDs (NRC, 2001) concluded that both structured and naturalistic behavioral approaches were effective in increasing communication, peer interactions, and social interactions, and reducing problem behaviors.

\section{Cognitive-Behavioral Interventions}

School professionals are being increasingly called upon to develop interventions for higherfunctioning students with ASDs (Safran \& Safran, 2001). These interventions differ from those for students with ASDs who have more significant cognitive and language impairments, instead focusing on core social impairments such as poor understanding of social conventions and interaction skills, and impaired social problem solving. Although controlled studies are lacking and empirical evidence just beginning to emerge, several studies have found cognitive-behavioral interventions to be effective in promoting social functioning (Kasari \& Rotheram-Fuller, 2005; White, Keonig, \& Scahill, in press). These interventions generally take advantage of the students' relative strengths in 
cognitive and language domains by using a combination of direct instruction, modeling, role-playing, performance feedback, and/or reinforcement. Group formats are common and offer a number of advantages including the opportunity to practice skills in a safe environment, opportunities to develop relationships with others around shared interests, exposure to role models, and establishment of relationships that extend beyond the group setting (Carter et al., 2004; Klin, McPartland, \& Volkmar, 2005). Researchers using cognitive-behavioral techniques in group-format have reported significant improvements in a range of areas such as social skills (Lopata, Thomeer, Volker, \& Nida, 2006; Webb, Miller, Pierce, Strawser, \& Jones, 2004), rates and duration of social interactions (LeGoff, 2004; Thiemann \& Goldstein, 2004), face recognition, and problem solving (Solomon, Goodlin-Jones, \& Anders, 2004). These preliminary findings suggest that cognitivebehavioral methods hold promise with this population.

\section{Psychopharmacological Interventions}

Psychopharmacological interventions have also been increasingly used in the treatment of ASDs. A number of students with ASDs exhibit problems with hyperactivity, inattention, restlessness, and impulsivity. Stimulants (e.g., methylphenidate) are the first line agents for these behaviors, while alpha- 2 adrenergic agonists (e.g., clonidine) and atypical antipsychotic medications (e.g., risperidone) are potential backup agents (Steingard, Connor, \& Au, 2005). In a review of 10 studies evaluating stimulants with the broader population of children with developmental disabilities including ASDs, Scahill and Martin (2005) reported that methylphenidate resulted in moderate to large improvements in a number of target behaviors such as inattention, hyperactivity, and irritability. Side effects associated with methylphenidate may include irritability, dysphoria, withdrawal, stereotypies, and insomnia (McCracken, 2005), and appear to be dose related.

The core symptoms of repetitive behaviors and resistance to change, as well as obsessivecompulsive and other anxiety symptoms are frequently treated with selective serotonin reuptake inhibitors (SSRIs; e.g., fluoxetine, fluvoxamine, sertraline). Although existing studies have been characterized by a lack of randomized placebo-controlled trials and small samples, positive effects have been reported, including reductions in compulsive and repetitive behaviors, rituals, and stereotypies (Findling, 2005; Scahill \& Martin, 2005; Steingard et al., 2005). Side effects of SSRIs may include agitation, insomnia, mood lability, nausea, and, occasionally, sedation. The tricyclic antidepressant clomipramine has also been used to treat repetitive behaviors, stereotypies, and obsessive-compulsive symptoms in ASDs. In a review of seven studies of clomipramine, Scahill and Martin (2005) reported that 6 of the studies found the medication to be effective in reducing target behaviors. However, clomipramine should be used with caution because of increased cardiac risks and lowering of the seizure threshold in a population vulnerable to seizures (Steingard et al., 2005).

A final behavioral cluster sometimes treated pharmacologically involves aggression, selfinjury, severe tantrums, and property destruction. Agents commonly used are from the drug class of atypical antipsychotics (AAPs; e.g., risperidone, olanzapine, etc.). Positive findings have included reductions in irritability, aggression, and self-injury, and some symptoms of anxiety, nervousness, and repetitive behavior (Findling, 2005; Scahill \& Martin, 2005; Steingard et al., 2005). AAPs offer an important alternative to the typical antipsychotic haloperidol, which, despite having positive effects for a number of problem behaviors in ASDs, can increase the risk of neurological side effects such as extrapyramidal symptoms and tardive dyskinesia (Findling, 2005; Scahill \& Martin, 2005; Volkmar et al., 2004).

\section{Future Directions}

Our professional knowledge of ASDs has come a considerable way since Lovaas' seminal intervention publication 20 years ago. Instruments intended to improve diagnosis have been published, behavioral and pharmacological treatments have received empirical support, and the neurological underpinnings of many of the symptoms have been elucidated. Given current prevalence and diagnostic trends, the role of school psychologists in the assessment and intervention of ASDs is likely to increase. 
The frontier now most in need of clarification is etiology. It is hoped the next decade will illuminate more specific genetic pathways and help us to better understand the nature of ASD subtypes. This will quickly lead to earlier diagnoses and, hopefully, individualized treatments based on discrete neurological findings and probable risks. If not a cure for autism, surely early identification aided by genetic advances and intensive individualized interventions based on genetic subtypes will succeed in mitigating many of the challenges now faced by those diagnosed with ASDs.

\section{References}

American Psychiatric Association (1994). Diagnostic and statistical manual for mental disorders (4th ed.). Washington, DC: Author.

Aylward, E. H., Minshew, N. J., Field, K., Sparks, B. F., \& Singh, N. (2002). Effects of age on brain volume and head circumference in autism. Neurology, 59, 175-183.

Bauman, M. L., \& Kemper, T. L. (2005). Neuroanatomic observations of the brain in autism: A review and future directions. International Journal of Developmental Neuroscience, 23, 183-187.

Bespalova, I. N., Reichert, J., \& Buxbaum, J. D. (2005). Candidate susceptibility genes for autism. In M. L. Bauman \& T. L. Kemper (Eds.), The neurobiology of autism (2nd ed.; pp. 217-232). Baltimore: Johns Hopkins University Press.

Bonora, E., Lamb, J. A., Barnby, G., Bailey, A. J., \& Monaco, A. P. (2006). Genetic basis of autism. In S. O. Moldin \& J. L. R. Rubenstein (Eds.), Understanding autism: From basic neuroscience to treatment (pp. 49-74), Boca Raton, FL: Taylor \& Francis.

Brock, S. E., Jimerson, S. E., \& Hansen, R. L. (2006). Identifying, assessing, and treating autism at school. New York: Springer.

Butter, E. M., Mulick, J. A., \& Metz, B. (2006). Eight case reports of learning recovery in children with pervasive developmental disorders after early intervention. Behavioral Interventions, 21, 227-243.

Buxhoeveden, D. P., \& Casanova, M. F. (2002). The minicolumn hypothesis in neuroscience. Brain, 125, 935-951.

Canitano, R., Luchetti, A., \& Zappella, M. (2005). Epilepsy, electroencephalographic abnormalities, and regression in children with autism. Journal of Child Neurology, 20, 27-31.

Carper, R. A., Moses, P., Tigue, Z. D., \& Courchesne, E. (2002). Cerebral lobes in autism: Early hyperplasia and abnormal age effects. Neuroimage, 16, 1038-1051.
Carter, C., Meckes, L., Pritchard, L., Swensen, S., Wittman, P. P., \& Velde, B. (2004). The friendship club: An after-school program for children with Asperger syndrome. Family Community Health, 27, 143-150.

Casanova, M. F. (2004). White matter volume increase and minicolumns in autism. Annals of Neurology, 56, 453.

Casanova, M. F., Buxhoeveden, D. P., Switala, A. E., \& Roy, E. (2002a). Minicolumnar pathology in autism. Neurology, 58, 428-432.

Casanova, M. F., Buxhoeveden, D. P., Switala, A. E., \& Roy, E. (2002b). Asperger's syndrome and cortical neuropathology. Journal of Child Neurology, 17, 142-145.

Casanova, M. F., Buxhoeveden, D. P., Switala, A. E., \& Roy, E. (2002c). Neuronal density and architecture (gray level index) in the brains of autistic patients. Journal of Child Neurology, 17, 515-521.

Chakrabarti, S., \& Fombonne, E. (2001). Pervasive developmental disorders in preschool children. Journal of the American Medical Association, 285, 3093-3099.

Chugani, D. C., Muzik, O., Behen, M., Rothermel, R., Janisse, J. J., Lee, J., et al. (1999). Developmental changes in brain serotonin synthesis capacity in autistic and nonautistic children. Annals of Neurology, 45, 287-295.

Cohen, D., Pichard, N., Tordjman, S., Baumann, C., Burglen, L., \& Excoffier, E. (2005). Specific genetic disorders and autism: Clinical contribution towards their identification. Journal of Autism and Developmental Disorders, 35, 103-116.

Cohen, H., Amerine-Dickens, M., \& Smith, T. (2006). Early intensive behavioral treatment: Replication of the UCLA model in a community setting. Developmental and Behavioral Pediatrics, 27, 145-155.

Courchesne, E., Karnes, C. M., Davis, H. R., Ziccardi, R., Carper, R. A., \& Tigue, Z. D., et al. (2001). Unusual brain growth patterns in early life of patients with autistic disorder: An MRI study. Neurology, 57, 245-254.

Courchesne, E., \& Pierce, K. (2005). Why the frontal cortex in autism might be talking only to itself: Local over-connectivity but long-distance disconnection. Current Opinion in Neurobiology, 15, 225-230.

Courchesne, E., Redcay, E., \& Kennedy, D. P. (2004). The autistic brain: Birth through adulthood. Current Opinion in Neurology, 17, 489496.

Coutinho, A. M., Sousa, I., Martins, M., Correia, C., Morgadinho, T., Bento, C., et al. (2007). Evidence for epistasis between SLC6A4 and ITGB3 in autism etiology and in the determination of platelet serotonin levels. Human Genetics, 121, 243-256.

Dalton, K. M., Nacewicz, B. M., Johnstone, T., Schaefer, H. S., Gernsbacher, M. A., \& Goldsmith, 
H. H. (2005). Gaze fixation and the neural circuitry of face processing in autism. Nature Neuroscience, 8, 519-526.

Delprato, D. J. (2001). Comparisons of discrete-trial and normalized behavioral language intervention for young children with autism. Journal of Autism and Developmental Disorders, 31, 315-325.

Dum, R. P., \& Strick, P. L. (2006). Cerebellar networks and autism: An anatomical hypothesis. In S. O. Moldin \& J. L. R. Rubenstein (Eds.), Understanding autism: From basic neuroscience to treatment (pp. 155-174). Boca Raton, FL: CRC Press.

Durand, C. M., Betancur, C., Boeckers, T. M., Bockmann, J., Chaste, P., Fauchereau, F., et al. (2007). Mutations in the gene encoding the synaptic scaffolding protein SHANK3 are associated with autism spectrum disorders. Nature Genetics, 39, 2527.

Dykens, E. M., Sutcliffe, J. S., \& Levitt, P. (2004). Autism and 15Q11-Q13 disorders: Behavioral, genetic, and pathophysiological issues. Mental Retardation and Developmental Disabilities Research Reviews, 10, 284-291.

Eikeseth, S., Smith, T., Jahr, E., \& Eldevik, S. (2007). Outcome for children with autism who began intensive behavioral treatment between ages 4 and 7: A comparison controlled study. Behavior Modification, 31, 264-278.

Fatemi, S. H. (2005). Reelin glycoprotein: Structure, biology and roles in health and disease. Molecular Psychiatry, 10, 251-257.

Fatemi, S. H., Halt, A. R., Realmuto, G., Earle, J., Kist, D. A., Thuras, P., et al. (2002). Purkinje cell size is reduced in cerebellum of patients with autism. Cellular and Molecular Neurobiology, 22, 171-175.

Fatemi, S. H., Stary, J. M., Halt, A. R., \& Realmuto, G. R. (2001). Dysregulation of reelin and Bcl-2 proteins in autistic cerebellum. Journal of Autism and Developmental Disorders, 31, 529-535.

Feng, J., Schroer, R., Yan, J., Song, W., Yang, C., \& Brockholt, A. (2006). High frequency of neurexin $1 \beta$ signal peptide structural variants in patients with autism. Neuroscience Letters, 409, 10-13.

Filipek, P. A., Accardo, P. J., Ashwal, S., Baranek, G. T., Cook, E. H., Jr., Dawson, G., et al. (2000). Practice parameter: Screening and diagnosis of autism: Report of the quality standards subcommittee of the American Academy of Neurology and the Child Neurology Society. Neurology, 55, 468-479.

Findling, R. L. (2005). Pharmacologic treatment of behavioral symptoms in autism and pervasive developmental disorders. Journal of Clinical Psychiatry, 66 (Suppl. 10), 26-31.

Fombonne, E. (2005a). Epidemiology of autistic disorder and other pervasive developmental disor- ders. Journal of Clinical Psychiatry, 66 (Suppl. 10), 3-8.

Fombonne, E. (2005b). Epidemiological studies of pervasive developmental disorders. In F. R. Volkmar, R. Paul, A. Klin, \& D. Cohen (Eds.), Handbook of autism and pervasive developmental disorders: Vol. 1. Diagnosis, development, neurobiology, and behavior (3rd ed., pp. 42-69). Hoboken, NJ: Wiley.

Goldstein, H. (2002). Communication intervention for children with autism: A review of treatment efficacy. Journal of Autism and Developmental Disorders, 32, 373-396.

Graf, E. R., Zhang, X. Z., Jin, S. X., Linhoff, M. W., \& Craig, A. M. (2004). Neurexins induce differentiation of GABA and glutamate postsynaptic specializations via neuroligins. Cell, 119, 10131026.

Harris, S. L., \& Handleman, J. S. (2000). Age and IQ at intake as predictors of placement for young children with autism: A four- to six-year followup. Journal of Autism and Developmental Disorders, 30, 137-142.

Howard, J. S., Sparkman, C. R., Cohen, H. G., Green, G., \& Stanislaw, H. (2005). A comparison of intensive behavior analytic and eclectic treatments for young children with autism. Research in Developmental Disabilities, 26, 359-383.

Kasari, C., \& Rotheram-Fuller, E. (2005). Current trends in psychological research on children with high-functioning autism and Asperger disorder. Current Opinion in Psychiatry, 18, 497-501.

Klin, A., McPartland, J., \& Volkmar, F. R. (2005). Asperger syndrome. In F. R. Volkmar, R. Paul, A. Klin, \& D. Cohen (Eds.), Handbook of autism and pervasive developmental disorders: Vol. 1. Diagnosis, development, neurobiology, and behavior (3rd ed., pp. 88-125). Hoboken, NJ: Wiley.

Koegel, R. L., Koegel, L. K., \& Brookman, L. I. (2003). Empirically supported pivotal response interventions for children with autism. In A. E. Kazdin (Eds.), Evidence-based psychotherapies for children and adolescents (pp. 341-357). New York: Guilford Press.

Lai, C. S. L., Fisher, S. E., Hurst, J. A., VarghaKhadem, F., \& Manaco, A. P. (2001). A forkheaddomain gene is mutated in a severe speech and language disorder. Nature, 413, 519-523.

Laumonnier, F., Bonnet-Brilhault, F., Gomot, M., Blanc, R., David, A., Moizard, M. P., et al. (2004). $\mathrm{X}$-linked mental retardation and autism are associated with a mutation in the NLGN4 gene, a member of the neuroligin family. American Journal of Human Genetics, 74, 552-557.

Lee, M., Martin-Ruiz, C., Graham, A., Court, J., Jaros, E., Perry, R., et al. (2002). Nicotinic receptor abnormalities in the cerebellar cortex in autism. Brain, 125, 1483-1495. 
LeGoff, D. B. (2004). Use of Lego as a therapeutic medium for improving social competence. Journal of Autism and Developmental Disorders, 34, 557571.

Lennon, P. A., Cooper, M. L., Peiffer, D. A., Gunderson, K. L., Patel, A., \& Peters, S. (2007). Deletion of 7q31.1 supports involvement of FOXP2 in language impairment: Clinical report and review. American Journal of Medical Genetics: Part A, 143A, 791-798.

Lopata, C., Thomeer, M. L., Volker, M. A., \& Nida, R. E. (2006). Effectiveness of a cognitive- behavioral treatment on the social behaviors of children with Asperger disorder. Focus on Autism and Other Developmental Disabilities, 21, 237-244.

Lord, C., Rutter, M., DiLavore, P., \& Risi, S. (1999). Autism Diagnostic Observation Schedule Manual. Los Angeles: Western Psychological Services.

Lord, C., Rutter, M., \& Le Couteur, A. (1994). Autism Diagnostic Interview-Revised: A revised version of a diagnostic interview for caregivers of individuals with possible pervasive developmental disorders. Journal of Autism and Developmental Disorders, 24, 659-685.

Lovaas, O. I. (1987). Behavioral treatment and normal educational and intellectual functioning in young autistic children. Journal of Consulting and Clinical Psychology, 55, 3-9.

Matson, J. L. (2007). Current status of differential diagnosis for children with autism spectrum disorders. Research in Developmental Disabilities, 28, 109-118.

Mayes, S. D., \& Calhoun, S. L. (2004). Influence of IQ and age in childhood autism: Lack of support for DSM-IV Asperger's Disorder. Journal of Developmental and Physical Disabilities, 16, 257272.

McConnell, S. R. (2002). Interventions to facilitate social interaction for young children with autism: Review of available research and recommendations for educational intervention and future research. Journal of Autism and Developmental Disorders, 32, 351-372.

McCracken, J. T. (2005). Safety issues with drug therapies for autism spectrum disorders. Journal of Clinical Psychiatry, 66, 32-37.

Mulder, E. J., Anderson, G. M., Kema, I. P., de Bildt, A., van Lang, N. D. J., \& den Boer, J. A. (2004). Platelet serotonin levels in pervasive developmental disorders and mental retardation: Diagnostic group differences, within-group distribution, and behavioral correlates. Journal of the American Academy of Child and Adolescent Psychiatry, 43, 491-499.

National Research Council (NRC). (2001). Educating children with autism. Committee on Educational Interventions for Children with Autism. Catherine Lord \& James P. McGee (Eds.). Divi- sion of Behavioral and Social Sciences and Education. Washington, DC: National Academy Press.

Newbury, D. F., Bonora, E., Lamb, J. A., Fisher, S. E., Lai, C. S. L., Baird, G., et al. (2002). FOXP2 is not a major susceptibility gene for autism or specific language impairment. American Journal of Human Genetics, 70, 1318-1327.

Noland, R. M., \& Gabriels, R. L. (2004). Screening and identifying children with autism spectrum disorders in the public school system: The development of a model process. Journal of Autism and Developmental Disorders, 34, 265-277.

Palmen, S. J., van Engeland, H., Hof, P. R., \& Schmitz, C. (2004). Neuropathological findings in autism. Brain, 127, 2572-2583.

Risi, S., Lord, C., Gotham, K., Corsello, C., Chrysler, C., \& Szatmari, P. (2006). Combining information from multiple sources in the diagnosis of autism spectrum disorders. Journal of the American Academy of Child and Adolescent Psychiatry, 45, 1094-1103.

Rogers, S. J. (2000). Interventions that facilitate socialization in children with autism. Journal of Autism and Developmental Disorders, 30, 399-409.

Rogers, S. J., Wehner, E. A., \& Hagerman, R. (2001). The behavioral phenotype in fragile X: Symptoms of autism in very young children with fragile $X$ syndrome, idiopathic autism, and other pervasive developmental disorders. Journal of Developmental and Behavioral Pediatrics, 22, 409-417.

Roussignol, G., Ango, F., Romorini, S., Tu, J. C., Sala, C., \& Worley, P. F. (2005). Shank expression is sufficient to induce functional dendritic spine synapses in aspiny neurons. The Journal of Neuroscience, 25, 3560-3570.

Rutter, M., Le Couteur, A., \& Lord, C. (2003). Autism Diagnostic Interview-Revised. Los Angeles: Western Psychological Services.

Safran, J. S., \& Safran, S. P. (2001). School-based consultation for Asperger syndrome. Journal of Educational and Psychological Consultation, 12, 385-395.

Santangelo, S. L., \& Tsatsanis, K. (2005). What is known about autism: Genes, brain, and behavior. American Journal of Pharmacogenomics, 5, 7192.

Scahill, L., \& Martin, A. (2005). Psychopharmacology. In F. R. Volkmar, R. Paul, A. Klin, \& D. Cohen (Eds.), Handbook of autism and pervasive developmental disorders: Vol. 2. Assessment, interventions, and policy (3rd ed., pp. 1102-1117). Hoboken, NJ: Wiley.

Schopler, E., Reichler, R. J., \& Renner, B. R. (1988). The childhood autism rating scale. Los Angeles: Western Psychological Services.

Schreibman, L., \& Ingersoll, B. (2005). Behavioral interventions to promote learning in individuals with autism. In F. R. Volkmar, R. Paul, A. Klin, \& 
D. Cohen (Eds.), Handbook of autism and pervasive developmental disorders: Vol. 2. Assessment, interventions, and policy (3rd ed., pp. 882-896). Hoboken, NJ: Wiley.

Schumann, C. M., \& Amaral, D. G. (2006). Stereological analysis of amygdala neuron number is autism. The Journal of Neuroscience, 26, 76747679.

Schumann, C. M., Hamstra, J., Goodlin-Jones, B. L., Lotspeich, L. J., Kwon, H., Buonocore, M. H., et al. (2004). The amygdala is enlarged in children but not in adolescents with autism; the hippocampus is enlarged at all ages. The Journal of Neuroscience, 24, 6392-6401.

Smith, T., Groen, A. D., \& Wynn, J. W. (2000). Randomized trial of intensive early intervention for children with pervasive developmental disorder. American Journal on Mental Retardation, 105, 269-285.

Solomon, M., Goodlin-Jones, B. L., \& Anders, T. F. (2004). A social adjustment enhancement intervention for high functioning autism, Asperger's syndrome, and pervasive developmental disorder NOS. Journal of Autism and Developmental Disorders, 34, 649-668.

Sparks, B. F., Friedman, S. D., Shaw, D. W., Aylward, E. H., Echelard, D., \& Artru, A. A. (2002). Brain structural abnormalities in young children with autism spectrum disorder. Neurology, 59, 184-192.

Spezio, M. L., Huang, P-Y. S., Castelli, F., \& Adolphs, R. (2007). Amygdala damage impairs eye contact during conversations with real people. The Journal of Neuroscience, 27, 3994-3997.

Steingard, R. J., Connor, D. F., \& Au, T. (2005). Approaches to psychopharmacology. In M. L. Bauman \& T. L. Kemper (Eds.), The neurobiology of autism (2nd ed., pp. 79-102). Baltimore: Johns Hopkins University Press.

Sutcliffe, J. S., \& Nurmi, E. L. (2003). Genetics of childhood disorders: XLVII. Autism, Pt. 6: Duplication and inherited susceptibility of chromosome 15q11-q13 genes in autism. Journal of the American Academy of Child and Adolescent Psychiatry, 42, 253-256.

Thiemann, K., S., \& Goldstein, H. (2004). Effects of peer training and written text cueing on social communication of school-age children with pervasive developmental disorder. Journal of Speech, Language, and Hearing Research, 47, 126-144.
Tuchman, R., \& Rapin, I. (2002). Epilepsy in autism. The Lancet: Neurology, 1, 352-358.

Tuchman, R. F., Rapin, I., \& Shinnar, S. (1991). Autistic and dysphasic children, II: Epilepsy. $P e$ diatrics, 88, 1219-1225.

US Department of Education, Office of Special Education Programs (2007). Annual report tables (data file). Available at http://www.ideadata.org/ AnnualTables.asp.

Volkmar, F. R., Lord, C., Bailey, A., Schultz, R. T., \& Klin, A. (2004). Autism and pervasive developmental disorders. Journal of Child Psychology and Psychiatry, 45, 135-170.

Volkmar, F. R., \& Nelson, D. S. (1990). Seizure disorders in autism. Journal of the American Academy of Child and Adolescent Psychiatry, 29, $127-$ 129.

Webb, B. J., Miller, S. P., Pierce, T. B., Strawser, S., \& Jones, W. P. (2004). Effects of social skill instruction for high-functioning adolescents with autism spectrum disorders. Focus on Autism and Other Developmental Disabilities, 19, 53-62.

White, S. W., Keonig, K., \& Scahill, L. (in press). Social skills development in children with autism spectrum disorders: A review of the intervention research. Journal of Autism and Developmental Disorder.

Wiznitzer, M. (2004). Autism and tuberous sclerosis. Journal of Child Neurology, 19, 675-679.

Wodrich, D. L., Kaplan, A. M., \& Deering, W. M. (2006). Children with epilepsy in school: Special service usage and assessment practices. Psychology in the Schools, 43, 169-181.

World Health Organization. (1992). International classification of diseases (10th ed.; ICD-10). Geneva, Switzerland: Author.

Yan, J., Oliveira, G., Coutinho, A., Yang, C., Feng, J., Katz, C., et al. (2005). Analysis of the neuroligin 3 and 4 genes in autism and other neuropsychiatric patients. Molecular Psychiatry, 10, 329332.

Yang, M. S., \& Gill, M. (2007). A review of gene linkage, association and expression studies in autism and an assessment of convergent evidence. International Journal of Developmental Neuroscience, 25, 69-85.

Yeargin-Allsopp, M., Rice, C., Karapurkar, T., Doernberg, N., Boyle, C., \& Murphy, C. (2003). Prevalence of autism in a US metropolitan area. Journal of the American Medical Association, 289, 49-55. 